\title{
MOVIMENTO DE REORIENTAÇÃO CURRICULAR DA SECRETARIA MUNICIPAL DE EDUCAÇÃo dE SÃo PAULO
}

\author{
João Paulo Subirá MEDINA*
}

Projeto: Ação pedagógica da escola pela via da interdisciplinariedade.

Entre as prioridades da Secretaria Municipal de Educação, nesta gestão, destaca-se a busca de uma Nova Qualidade de Ensino. Esta prioridade vem se concretizando desde 1989 por várias ações, entre as quais o Movimento de Reorientação Curricular.

Reafirmamos aqui que o atendimento de reorientação curricular $\in$ um processo de construção coletiva do qual participam, necessariamente, diferentes grupos de interlocução: a escola, a comunidade $e$ os especialistas nas diferentes áreas do conhecimento. Os dois primeiros momentos deste movimento, a Problematização e a Sistematização (em seu primeiro nivel) atingiram a rede e toda a sua extensão e modalidades de ensino.

A reorientação curricular prévia garante o estímulo e o apoio ao desenvolvimento de projetos gerados pelas próprias escolas, buscando avançar na direção de sua autonomia.

Simultaneamente, conforme havia sido previsto, iniciou-se o projeto de interdisciplinariedade.

As equipes multidisciplinares dos Núcleos de Ação Educativa, Diretoria de Orientação Técnica e das Escolas Piloto, com assessoria de professores universitários, empenharam-se na construção coletiva dos caminhos desta proposta. Aconteceram conquistas, confrontos e conflitos; viveram-se ansiedades, alegrias e tristezas.

\section{FUNDAMENTOS DO PROJETO}

Introdução

A questão da escola pública brasileira apresenta-se hoje como um desafio a ser superado. Há consenso em relação à crise pela qual todos passamos. No entanto, o sonho e o desejo da transformação existem. As falas freqüentes $\mathrm{e}$ as atitudes isoladas de educadores mais críticos bem o demonstram.

Um grande problema exige uma grande solução e o que aqui se entende como solução é mais do que reforma: mudança; mais do que mudança: transformação.

Transformar implica em agir, agir conscientemente. Ação global, coletiva, entendendo a escola como mais do que a soma de suas partes.

A escola do real vivido que se relaciona organicamente com a comunidade na qual está inserida. Espaço significativo de construção do conhecimento.

Que escola é essa que queremos transformar?

O Documento 2, "O Movimento de Reorientação Curricular na Secretaria Municipal de Educação de São Paulo 1990", explica algumas características dessa instituição. 
Mostra uma escola que dificilmente consegue voltar seus olhos para si mesma numa dimensão crítica. Uma escola que quase sempre se acomoda à situação política vigente, aguardando soluçōes mágicas, prontas, de fora para dentro e de cima para baixo.

Uma escola que, teoricamente colocada a serviço da população, isola-se em relação à comunidade na qual está inserida. Isolamento que se coloca em dois níveis: na não consulta da comunidade para o planejamento da ação educativa e na despreocupação com a realidade local.

Outra característica apontada na fala problematizadora dos educadores, $\varepsilon$ que o conhecimento,

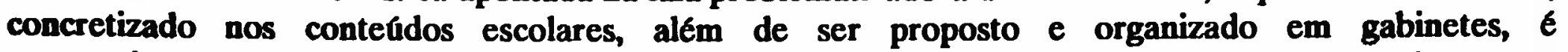
compartimentalizado e fragmentado artificialmente, havendo uma desconsideração total com a interdisciplinariedade natural do objeto do conhecimento.

Como fruto que somos dessa instituição em crise, nos acostumamos a receber propostas pedagogicas que nem sempre atendem às especificidades da comunidade escolar; a usar livros didáticos como instrumentos únicos do nosso fazer pedagógico; a não discutir questões educacionais mais amplas e a nos isolarmos a ponto de não perceber o que acontece além das quatro paredes de nossa classe. Perdemos por conseqüência, a motivação, não nos percebendo como sujeitos do fazer educativo e portanto, deixando de construir nossa própria identidade.

Este sistema que nos leva a analisar os efeitos, sem atacar as causas, nos mostra um quadro eufemisticamente chamado de fracasso escolar - evasão e repetência - que vem sendo enfrentado, ainda de maneira pontualizada, por educadores comprometidos com a mudança.

Tais iniciativas apontam para a construção de uma escola que se quer participativa e decisiva na formação do sujeito social, que considere como organismo vivo (pensante e participante) a comunidade escolar que a usa e que a faz. Uma escola onde o educador seja sujeito de sua ação, capaz de refletir e alterar programas e métodos; capaz de inserir sua escola, primeiramente numa comunidade que the dá razão de existir e depois, num sistema maior que se quer transformar.

Nessa direção e tendo em vista a experiência acumulada pelo trabalho realizado nas dez escolas-piloto, que vem demonstrando ser possível a construção de uma nova escola, submetemos aos educadores do Ensino Municipal de São Paulo a presente proposta de fazermos, juntos, um outro caminho. Assim como na relação conhecimento-comunidade, esta proposta só terá sentido e significado se para ela convergir a força criadora e transformadora que hoje habita a escola, à espera do momento e da oportunidade de constituir-se como tal.

\section{Principios e prioridades}

Qualquer que seja a aproximação que a escola faça desta proposta, os princípios e as prioridades deverão estar garantidos. Dessa forma, esta proposta de ação pedagógica da escola pela via da interdisciplinariedade considera, pressupõe e realça a participação e a descentralização como fundamentais à autonomia, que são os três princípios que norteiam nossa política educacional. São, em verdade, princípios que apontam práticas avançadas e de difícil, mas não impossível, construção. Tanto a participação de educadores, educandos e comunidade, quanto a descentralização levam ao poder compartilhado. De um lado, a administração deixando de ser a única responsável por decisões da escola e de outro, a escola, na figura de seus dirigentes e coordenadores, deixando de ser senhora absoluta de todas as decisões. Compartilhar um poder na direção da construção da autonomia, contextualiza a participação dos educadores em decisōes que dizem respeito, rigorosamente, ao seu pensar e fazer pedagógico. A escola deve sentir-se à vontade na questão da participação e da autonomia; são princípios fundamentais para 0 envolvimento dos educadores numa proposta que exige de cada um, individualmente, e de todos, coletivamente, uma superação do individualismo e coletivismo fragmentados. Participação e autonomia completam-se e constituem-se um dos sustentáculos das prioridades estabelecidas, entre elas, uma nova qualidade de ensino que está proposta e vem se desenvolvendo através da Reorientação Curricular e da Formação Permanente. A ação pedagogica da 
escola pela interdisciplinariedade se ap6ia na intersecção de ambos: de um lado, uma revisão - e por conseguinte, ampliação - do conceito de curriculo que, como instrumento de organização e ação da escola, extrapola os limites da grade curricular e avança para ouvir a comunidade, extrapola a mera função transmissora de conteŕdos e recoloca a discussão do como, do porque, do que e do para que; do outro lado, a certeza de que qualquer ação de reorientação curricular deve apoiar-se numa frente de formação permanente dos educadores. Como o pensamento e a linguagem, uma a determinar o outro, 0 Movimento de Reorientação Curricular e a Formação Permanente são faces da mesma moeda, em busca de uma nova qualidade de ensino, apoiada na autonomia da escola.

O projeto que ora apresentamos pressupõe e exige mudanças de ordem curricular, numa perspectiva emancipadora. Pressupõe e exige mudanças de posturas, pressupõe e exige querer construir a autonomia da escola.

Há justificativas para isso:

\section{Justincativas}

Há muitas justificativas para a mudança da escola que quer uma nova qualidade de ensino.

Esta proposta justifica-se e se propõe rever:

a) a relação educador/educando, de forma a:

- superar o individualismo nas relaçōes com os alunos;

- possibilitar e encorajar o educador a ser solidário com o outro;

- entender-se que ambos são sujeitos da ação educativa e da construção do conhecimento;

- estimular uma relação de igualdade, respeito e consideração mútua, enquanto seres que se relacionam com e pelo conhecimento, ainda que de modos diferentes quanto à intensidade e profundidade;

- superar o estigma da educação bancária, em que educadores sabem e depositam o conteúdo em educandos que não sabem.

b) a concepşão do conhecimento, de forma a:

- compreender que o conhecimento não é estático e nunca está acabado: é dinâmico e pode ser recriado, reinventado;

- perceber que o conhecimento é resultado das relações que o homem estabelece com o mundo e consigo mesmo com vistas à instrumentalização para intervenção na transformação da realidade;

- lidar com a relatividade do conhecimento, que se constrói em comunhão com outros homens, marcados pelo contexto histórico e social;

- lidar com a pluralidade do conhecimento, superando as noções de "verdades absolutas" e do "certo e errado";

- descobrir uma forma de considerar que o conhecimento não se constroi, apenas pela razão, mas também pela emoção e afetividade.

c) a dimensão dos conteúdos na aprendizagem escolar, de modo a:

- rever a relação entre os conteúdos e a realidade, de forma que esta seja o objeto de estudo e significado daqueles;

- buscar conterudos significativos com vistas a explicar melhor a realidade concreta;

- redimensionar a relação entre o conhecimento popular, de senso comum, e o conhecimento acumulado pela humanidade;

- compreender que os conteúdos escolares não têm fim em si mesmos, mas têm importância como explicitadores e desveladores de uma realidade em que se pode intervir;

- entender a natureza interdisciplinar. 
d) o conceito de currículo, de modo a:

- entender o currículo como o instrumento básico de que a escola dispõe para organizar sua ação transformadora;

- entender o currículo de forma mais ampla, extrapolando a grade curricular, englobando todas as ações e relações, de fora para dentro e de dentro para fora, propostas e existentes, pela e para a escola;

- perceber o currículo na perspectiva da gestão democrática da escola como uma construção em processo, portanto diretamente relacionado ao coletivo da escola através do planejamento participativo;

- compreender esta forma de organização curricular como dinâmica e que pode ser e ter sua ação reorientada com freqüência.

e) o papel da escola, de modo a:

- perceber a escola como um local privilegiado de receber e considerar a cultura da comunidade e de irradiar outras formas e manifestações culturais;

- perceber a escola como local de reflexão, estudo e construção conjunta do conhecimento;

- entender e valorizar a escola como espaço de participação e organização dos diferentes segmentos e movimentos sociais;

- valorizar a escola como o espaço de construção individual e coletiva da ação pedagógica, numa perspectiva de resgatar o educador no educador;

- compreender a função política da escola, numa perspectiva de saber o saber como instrumento de luta na transformação da história.

\section{Objetivos}

As justificativas anteriormente descritas apontam para os seguintes objetivos:

- rever a delimitação dos papéis de educando, educadores e comunidade;

- encontrar, através de estudos e reflexões coletivas, uma prática de um saber não fragmentado;

- recuperar o papel do educador enquanto produtor e criador de conhecimento e organizador de sua prática, mantendo-se e incentivando-se a unidade teoria e prática;

- vincular a construção do conhecimento à realidade em que a escola está inserida;

- reforçar o caráter dinâmico do conhecimento;

rever o papel da escola com vistas à melhor compreensão da realidade para uma possível intervenção nessa realidade;

- incentivar a escola a encontrar-se como um centro de produção, recriação e irradiação de culturas;

- priorizar, sobre todas as outras formas, a construção coletiva da ação pedagógica e da escola.

\section{O PAPEL da EdUCAÇÃo física No PROJeTO:}

Da Educação Física que fazemos para a Educação Física que queremos, duas visões da área.

Introduçåo

No momento em que a Secretaria Municipal de Educação de São Paulo empenha-se em melhorar a qualidade do ensino público, inspirada em diretrizes político filosoficas de caráter popular e 
democrático, acreditamos que o Projeto de Reorganização da Escola, via AÇÃo PEDAGÓGICA INTERDISCIPLINAR, oferece uma oportunidade ímpar no sentido de exercitarmos uma prática que busque superar o modelo de uma educação unilateral, ainda prevalecente na estrutura escolar.

E preciso romper esta unilateralidade do trabalho intelectual, super-racionalizado e fragmentado, para dar vazão a novas formas e conteúdos que não desprezem a educação dos sentidos em toda a sua amplitude e que, sem negar a realidade histórica, exerça uma resistência que aponte dialeticamente para uma nova ordem social, calcada na aplicação de princípios verdadeiramente democráticos e de justiça para todos.

E nesta perspectiva que achamos que a Educação Física, se entendida como disciplina que valoriza sua praxis (ação/reflexão/ação), pode dar uma grande contribuição neste esforço coletivo de construção de uma escola que, alem de permitir o conhecimento crítico da realidade, seja também canal privilegiado de produção de cultura, onde os sentimentos, a criatividade, o ludico, a corporeidade, enfim, não fiquem do lado de fora.

\section{Primelra visāo: a perspectiva tradicional/conservadora (Concepção Positivista-Funcionallsta)}

Características desta visão:

1. Dá ênfase às dimensões biológicas ou bio-psicológicas dos alunos, reduzindo os seres humanos às suas dimensões biológicas ou bio-psicológicas, ou seja, considerando "as partes" como sendo o todo.

2. Tem uma preocupação fundamental com o "físico", com o movimento em seus aspectos mais mecânicos, promovendo uma "educação do físico" e incorporando uma visão de saúde de indole biofisiologica (reducionista).

3. Dá prioridade absoluta aos aspectos anátomo-físiologicos; os aspectos psicológicos são incorporados apenas na medida em que possam interessar ou interferir na performance; adota, portanto, o paradigma da Aptidão Física.

4. Concebe o CORPO HUMANO de forma dualista ou pluralista; ou seja, vê o Homem dividido em partes ou substâncias distintas: corpo e mente, corpo e alma, corpo, mente e espírito...

5. Freqüentemente vê o aluno como um atleta e este como uma máquina; o corpo nesta perspectiva passa a ser considerado como objeto de produção, reprodução ou consumo.

6. Reforça consciente ou inconscientemente o individualismo, ao descontextualizar a sua prática das contradições sociais.

7. Devido ao universo de seu saber ser essencialmente tecnicista (reducionismo técnico), tende a estabelecer uma relação de autoritarismo com os alunos, pois, neste aspecto (conhecimento técnico), o professor $\boldsymbol{\epsilon}$ o unico detentor do conhecimento; o professor sabe tudo e os alunos nada sabem.

8. Tende a utilizar-se das técnicas corporais da moda, de forma mecanicista, reproduzindo modelos sem uma análise mais profunda de seu significado social e cultural.

9. Vê a competição como um fenômeno intrinsecamente positivo para a formação dos alunos, independentemente das intenções subjacentes no processo educativo; não se apercebe dos limites onde se reproduz a competição doentia, enquanto produto social a ser combatido.

10. Além dos reducionismos biológico, biopsicológico e técnico, tende também ao reducionismo pedagógico (pedagogização) de suas práticas, ao considerar a Educação Física em si mesma, a escola em si mesma, a criança em si mesma..., sem considerar as diferenças econômicas, de classe social, culturais, que caracterizam os diversos grupos sociais.

11. Reproduz e reforça consciente ou inconscientemente os valores dominantes; o professor, nesta perspectiva, acaba sendo simples instrumento reprodutor da engrenagem social, vale dizer, simples objeto da história; as atividades físicas servem para desenvolver o individuo física e mentalmente, plenamente adaptado à estrutura social vigente, desempenhando "da melhor maneira possivel" a sua função nesta sociedade. 
Segunda visão: A perspectiva progressista/transformadora (Concepsão Histórico-Crítica)

Características desta visão:

1. Dá ênfase ao ambiente sócio-cultural e à história concreta das pessoas, sem desconsiderar as outras dimensões (biologica, psicológica, etc).

2. Tem uma preocupação fundamental com o movimento enquanto expressão de uma cultura viva e enquanto caminho para o aperfeiçoamento ou transformação da sociedade; aqui a saúde $\epsilon$ vista mais como resultado do estágio de desenvolvimento da sociedade (conquista ou atendimento das necessidades básicas: alimentação, saneamento básico, educação, tempo livre) do que o resultado de um processo individual.

3. Dá prioridade ao sentido da existência das pessoas como um todo, a partir da própria especificidade do movimento humano (jogo, brincadeira, prática desportiva, dança).

4. Concebe o corpo humano de forma global e integrado à natureza e à sociedade; não reconhece a mente, a alma, o espírito, enquanto manifestações humanas, fora da corporeidade; Corpo, Natureza e Sociedade são dimensões interdependentes desta existência.

5. Vê o aluno como um Ser verdadeiramente humano, ou seja, um Ser carente em busca de sua transcendência (superação de si mesmo) e de sua realização enquanto ser social.

6. Combate o individualismo; entende o ser humano (o corpo) como sujeito da história, mas também (e fundamentalmente) como produto desta história construída pelos homens; respeita e ajuda a consolidar a individualidade das pessoas.

7. Com uma sólida e dinâmica visão de Homem e de mundo (multidisciplinar), conquista a autoridade, que não se esgota apenas na sua competência técnica, mas que vai mais além à medida que se dá conta de suas expressões e manifestações mais amplas de vida, onde a cultura corporal se insere.

8. Utiliza-se de técnicas corporais (milenares ou contemporâneas) de uma forma crítica e em consonância com a realidade em que se trabalha, procurando perceber que toda a ação motora $\epsilon$ uma produção histórica, possuidora de um significado social e cultural definido.

9. Utiliza-se da competição como um elemento educativo numa determinada direção que aponta para um desenvolvimento humano que persegue conscientemente e a todo momento a justiça, a fraternidade e a solidariedade entre os homens.

10. Está fundamentada no concreto: sua escola não é qualquer escola, seus alunos não são quaisquer alunos, as crianças não são quaisquer crianças. Cada pessoa tem a sua história, a sua classe social e portanto, os seus valores, as suas aspirações, os seus desejos, o seu desenvolvimento e as suas contradições.

11. Busca a todo momento reconhecer-se como sujeito, capaz de socialmente contribuir no esforço coletivo de transformação dos valores dominantes; as técnicas corporais são entendidas dentro de um contexto cultural-social dinâmico com potencialidades transformadoras.

\author{
João Paulo Subirá Medina (Assessor-coordenador) \\ Celi Nelza Zulke Taffarel (Assessora) \\ Carmem Lúcia Soares (Assessora) \\ Ma. Heloisa L.M.Forjaz(Coordenadora dos representantes) \\ Noely Gutierre Molinaro (Representante do NAE 02) \\ Márcia Fernandes Sfakianavis (Representante do NAE 03) \\ Maria Cecília Malaman (Representante do NAE 04) \\ Arimary Alencar Boccoli (Representante do NAE 09) \\ Geni A. dos Santos Nery (Representante do NAE 10)
}

EQUIPE DE ESPECIALISTAS DA ÁREA DE EDUCAÇÃO FISICA ESCOLAR: 